contrary to the general belief that the two ferments rise and fall together, so that coagulation of milk may be employed as an easy, though indirect, test of peptic power. The second point deserving attention is that the patient, first seen in consultation during November, showed an increasing pyloric stenosis with obstinate constipation and the return of food and drink by vomiting. About Jan. 1, 1899, the diagnosis of cancer was verified by the finding of cancer nests microscopically in the wash-water of the jejune stomach. After this the pyloric stenosis rapidly abated, the patient gained somewhat in weight, the stomach returned to normal size, vomiting became infrequent and it is only recently (note made April 28) that the signs of stenosis have been again manifest. (The patient has since died.)

Mrs. P. had passed the test breakfast into the intestine by the end of the first hour, so that, for the next meal, meat was added. The rapidity of the passage of food through the stomach is shown here, also in that only 75 c.c. remained of a meal amounting to about 400 c.c. Her stomach was somewhat larger than normal, but under the circumstances it might be more appropriate to use the term "megalogastria" rather than dilatation to describe her condition, the latter term being usually associated with more or less gastric stagnation. The digestion of the dissolved starch had been completed and all the maltose absorbed, yet the precipitate of peptone made up half of the volume of the filtered chyme The large combined acidity, with total lack of free $\mathrm{HCl}$, is probably in intimate relation with these two facts. This case shows the maximum of peptone production observed by the writer.

W. F. V. was the patient of a neurologist, referred for examination on account of complaint of gastric symptoms. The analysis and physical examination failed to reveal stomach trouble. It will be noted that the quantitative estimation of proteids, though rather high in each instance, did not pass the normal limits.

F. K., who had previously suffered from atonic dilatation of the stomach with obstinate subacidity, remained well for two or three years and then presented himself with typical symptoms of hyperchlorhydria. The result of the examination shows how erroneous this preliminary diagnosis was ard emphasizes the impossibility of making accurate diagnoses of gastric troubles by symptomatology alone. Proteolysis was practically normal, though syntonin was rather high.

G. L. presented no peculiarities beyond those clearly shown in the table. It may be said in general that the pathologic series shows a higher average of the preliminary proteids and a variable condition of peptone.

C. L. B. represented what may properly be termed a nervous dyspepsia, as, even after the restoration of his gastric motor function, he continued for some time to complain of symptoms of stagnation.

J. J. M. showed at several previous examinations a marked diminution of hydrochloric acidity, even after two or three hours of gastric digestion. He had an attack of what was described by his home physician as subacute scolecitis, toward the close of his treatment for the gastric condition. The latter was regarded as an independent affection, not a reflex from the bowel, on account of a distinct history of hematemesis. In spite of this interruption, the subsequent course of the gastric lesion was favorablé.

Mrs. J. P.'s case was remarkable in that there was not a general splanchnoptosis, in spite of the marked prolapse of the stomach-the lesser curvature being just above the umbilicus-and the movability of the right kidney. The esophagus was dilated, 250 c.c. of distinctly esophageal mucus being romited at one time and the gastro-diaphane kinking without reaching the stomach, its stiff end of nearly two inches having turned within the esophagus.

Dr. R., in spite of considerable subjective discomfort and of the physical abnormalities of the stomach and liver, showed a good and consistent chemic condition.

Mrs. Mc.'s examination also resulted consistently, except that stagnation was not in evidence.

Notes on Chemic Examinations.-Acidity in No. 9 was taken from similar sample next day.

In Nos. 1, 7, 13, 24, resorcin and sugar used as indicator for frce $\mathrm{HCl}$; in others dimethyl-amido-azobenzol. The former method is more tedious, but more accurate. Phenolphthalein used as indicator for total acidity in all examinations. Percentages refer to c.c. of $\mathrm{n} / 10 \mathrm{NaOH}$ solution, as compared with number of c.c. unfiltered chyme.

Diagnosis in Nos. 21 and 22 made from microscopic recognition of fragment of tumor. No. 21 died eight months after this examination.

Combined $\mathrm{HCl}$ by alizarin, 66 per cent. for No. 23, 25 per cent. for No. 24; in Nos. 25 and 26, free $\mathrm{HCl}$ perhaps disguised by presence of blood from siphonage. In No. 27 , combined HCl, 45 per cent.

\section{THE RAGE FOR RAPID OPERATING AND THE IMPORTANCE OF SAVING TIME IN SURGICAL OPERATIONS. JOHN S. MILLER, A.M., M.D.}

Ex-Surgeon to St. Joseph's Hospital of Philadelphia; Demonstrator of Anatomy, Gross Medical College. DENVEI, COLO.

The question of time consumed in surgical operations is an important one. In the pre-anesthesia days time meant much to the unfortunate victim, whose vitality or resisting power was already reduced by nauseating and depressing drugs, such as infusion of tobacco, opium, etc., given with a view to benumbing the sensibility of the patient, who was frequently held by a corps of powerful assistants, or fastened to the operating-table by straight-jackets, straps or other devices. Dexterity and speed on the part of the surgeon then were indeed desirable factors to the shrieking and suffering patient.

The introduction of anesthesia lessened the necessity for speed, and also removed the disturbing elements which may have interfered with the accurate fulfilment of delicate operations. Anesthesia, when properly induced, produces a tranquility in the patient, operator, and assistants, which is highly essential for the proper and successful progress of the operation. In this, however, many surgeons permit themselves to drag in their work, and for the time seem to forget that the state of general anesthesia is a dangerous one and that not a minute should be wasted. It is a well-established fact that prolonged anesthesia is a retarding element in the convalescence of the patient. This is the more prominently exemplified in a complicated abdominal case, in which the resisting power of the patient has been stimulated to a point when it is estimated that the patient has a chance to survive the operation. The anesthesia, exposure and manipulation of the peritoneal cavity for from one-half to three hours, with a physically bankrupt patient is a very important factor in the prognosis. These facts being accepted, time is as important an element to success as asepsis or correct methods in operating. 
It is quite common in hospital clinics for the operator to lecture to his class while leaning over his work, and, frequently straightening up to address the students, and thus many valuable minutes are lost. A very wise practice is now being introduced in the German clinies. The professor operates, while one of his clinical assistants lectures to the class, or vice versa. The operator can thus concentrate his mind on the important task before him. Professor Albert, of Vienna, lectured to the students while his assistant, Ewald, operated. This method is advantageous to both patient and student. But few are endowed with the ability to lecture and operate simultaneously.

An operation should be done with despatch, without the semblance of undue haste or attempt at show, flourish or brilliancy. Such "speed" should be consistent with good conscientious work and the best results. Despatch in surgical operations is often misconstrued as haste and carelessness by jealous rivals. The operator is rapid whose equipment is thorough from his anesthetizer and first assistant to the application of the safety-pin which secures the final turn of the bandage. He accomplishes his object who does not allow his plans to be modified by suggestions from visitors or guests, who is prepared to promptly combat any emergency that may arise, who operates deliberately, who does not drop his instruments on the floor, and who, in picking up an instrument from the tray, does so for a definite purpose. Such an operator knows what he wants two or three stages in advance, and gives his orders accordingly, so that there shall be no loss of time. His assistants are well trained ("team work") and comprehend his wants by a look or gesture, thus avoiding misunderstanding, conflicting orders and collisions.

It is in the saving of the minutes and avoidance of unnecessary delays that the minimum amount of time is consumed in performing the operation. Such methods should constitute "rapid operating."

\section{VENEREAL DISEASE AS A SOCIAL PROBLEM.*}

$$
\begin{aligned}
& \text { W. C. GATES, M.D. } \\
& \text { ROCKLAND, MICH. }
\end{aligned}
$$

When studying medicine I was taught, not only by one but by many, that if I would attain to the greatest degree of success in the profession I must treat every patient who presented, no matter what his social position or standing, age, or other condition, as if he were infected with venereal disease until I had proved to the contrary. At that time I could not fully credit the statement and questioned the observation of the men who made it. I entered practice about ten years ago, in a town with an average population of 500, which for all practical purposes of this paper is an ordinary country village, isolated from the rest of the world and a great distance from any city. There was no house of prostitution in the township, and no public prostitute has existed within its borders since my residence there, but time and experience have convinced me that my teachers were right in their statement.

Syphilis is a terrible disease and is so recognized by the laity, while the great majority regard gonorrhea as a trivial affection. To my mind it is tenfold more terrible than syphilis, while both diseases cause untold suffering to innocent parties, and during my very limited experience I have seen several blind from the dis-

- Presented to the Section on Hygiene and Sanitary Science, at the Fifty-first Annual Meeting of the American Medical Association, held at Atlantic City, N. J., June 5-8, 1900. ease. The year I entered the town a young man from one of the best families graduated from one of our schools; a few years later, while on a business trip outside, he contracted gonorrhea, was treated and, as he supposed, cured by a frieend who had suffered several times in the same way. Soon after his return home he was married to a young woman whom I remember as a bright, robust, rosy-cheeked schoolgirl. Since then I have treated the man for stricture and his wife for all the evils following a gonorrheal infection of the pelvic organs. She is pale, anemic, a daily sufferer, and spends nearly a week out of each month in bed. Without children, in a beautiful home, she will drag out her life of misery and suffering.

A farmer's daughter, whom I remember as a beautiful schoolgirl, a perfect type of physical strength, two years ago married a man who bragged of the number of times he had contracted gonorrhea. Soon after marriage her troubles began, her strength failed and physical exertion became a source of discomfort and pain until she was unable to do her own housework. A few months ago I operated on her for pelvic peritonitis.

A year ago I knew a man, with a wife and four children, who possessed a good income and a happy comfortable home. He contracted gonorrhea, infected his wife before he knew it, became frightened and used socalled heroic treatment, and is now at Mt. Clemens under treatment for gonorrheal rheumatism, his wife is in a Chicago hospital to undergo an operation for salpingitis, the home is sold to pay the expenses, and the children are cared for by strangers.

I would ask my hearers to lay aside all prejudice and consider this subject in the true scientific spirit, going back to the fundamental underlying principles: 1 , the passions actuating those who keep this evil in existence; 2 , the breeding of children and the hereditary mental influence to which they are subjected; 3 , the want of police and medical supervision through a morbid sentiment and a lack of knowledge in a class which wields the greatest influence.

I will first define a passion as a certain movement of the mind which not only influences, but predominates and controls the entire organism. What is the one supreme passion in man? What is the one supreme passion which actuates and controls, not only man, but all living organisms, without which, if suppressed, all life would soon cease to exist? The answer is plain-the sustenance of life. The passion which ranks next to this and nearly equals it in power is the propagation of life. If either of these passions were suppressed all life would soon cease to exist. They are unchangeable laws of Nature and no arbitrary law of society can suppress them or control them except to a very limited extent. These facts should never be lost to sight. Prostitution finds the reason for its existence in one of these passions, and if society would protect itself from the evils arising from prostitution it must study the subject carefully and act on reason instead of prejudice.

I believe much of the evil can be prevented and, as the acme of medical science is the prevention of disease, that this problem is pre-eminently one for the attention of the Association. It can not be left to the church, as she is unable to cope with it, and her influence, when brought to bear on this subject, has invariably been unsatisfactory. Churchmen are educated along different lines, seldom taught to differentiate fact from theory, or to reason from effect to cause, and they appeal largely to the sympathies and prejudices of those whom 